\title{
GUERRA, LOCURA E HISTORIA. LA HISTORIOGRAFÍA FRENTE A LOS DESTINOS DEL LAZO SOCIAL Y SU DISLOCACIÓN
}

\author{
War, madness and History. Historiography faced with social bond paths and its \\ dislocation
}

Mariana Leconte*

\section{Resumen}

El artículo pone en relación la guerra -descripta en su lógica desde conceptos levinasianos - con la noción psicoanalítica de "trauma" y pregunta, a partir de allí, por sus consecuencias destructivas del lazo social. En este contexto teórico, se interroga sobre el carácter del relato historiográfico, estableciendo una analogía entre su intención de escritura y la marcación de letras en el borde de lo real-traumático. El trabajo recorre los conceptos de guerra, nueva racionalidad y subjetividad hilvanados por Levinas en el prólogo a su gran obra Totalidad e Infinito, oponiendo su articulación a la lógica hegeliana; además, construye la relación entre guerra, trauma y dislocación del lazo social a partir de textos psicoanalíticos clásicos de Freud y Lacan y otros que abordan específicamente esta relación como el de los psicoanalistas Jean Max Gaudillière y Françoise Davoine, Historia y Trauma.

$$
<\text { Guerra }><\text { trauma- }><\text { escritura }><\text { Historiografía }>
$$

\begin{abstract}
The article connects war-described in its logic from levinasian concepts- with the psychoanalytical notion of "trauma" and asks, from that point on, for its consequences on the social bond destruction. In this theoretical context, it examines Historiography, setting its writing intention in analogy with the letters' branding in real-traumatic borders. This work examines the concepts of war, new rationality and subjectivity sketched by Levinas in the preface of his major work Totality and Infinity, opposing its articulation to the Hegelian logic. Furthermore, it builds the relation between war, trauma and social bond dislocation from classical psychoanalytical texts by Freud and Lacan, and others that specifically deals with this relation, as is the case of Jean-Max Gaudillière and Françoise Davoine's History and Trauma.
\end{abstract}

$<$ War $><$ trauma $><$ writing $><$ Historiography $>$

Recibido: 03/09/2015 // Aceptado: 28/10/2015

* Dra. en Filosofía, Investigadora Asistente-Profesora Adjunta, Instituto de Investigaciones Geohistóricas (CONICET/UNNE), Departamento de Filosofía - Facultad de Humanidades (UNNE). marianaleconte@hotmail.com 


\section{Introducción}

$\mathrm{Si}$ "la locura tiene que ver con una dislocación radical del lazo social", según afirma Gerard Fromm, en el prólogo al libro de Françoise Davoine y Jean-Max Gaudillière Historia y trauma (Davoine y Gaudillière, 2011: 17), y la guerra produce esta destrucción masiva no sólo de los individuos sino también del mundo material y simbólico que habitaron, y "suspende la moral" convirtiéndola en irrisoria, como sostiene Emmanuel Levinas en Totalidad e Infinito (Levinas, 1977), puede entreverse el impacto de toda guerra sobre la cultura y las subjetividades.

Frente a esto, el gesto historiográfico se comprende como la construcción de un relato y, en el caso particular de la historia de la guerra, de un relato en torno de lo indecible.

En este artículo, abordaremos la pregunta por el carácter y el alcance de este gesto, desde un punto de vista filosófico y desde los préstamos facilitados por los conceptos psicoanalíticos de trauma y lazo social. Sobre esta base, intentaremos discutir la relación entre el carácter del gesto historiográfico y sus modos posibles de producción.

El desarrollo se dividirá en tres parágrafos: en el primero, se presentará -a modo de marco general- la confrontación de dos modalidades de comprensión de la guerra y su violencia, tributarias de dos modos radicalmente diferentes de asumir lo racional; en el segundo, con el recurso a las nociones psicoanalíticas de trauma y lazo social, se mostrará en qué sentido esa violencia de la guerra es traumática y se ponderará analíticamente sus efectos en la trama social; en el tercero y último, una vez determinado adecuadamente el escenario abierto por la guerra, se buscará reconsiderar el carácter de las tareas a que es convocado, en este contexto, el gesto historiográfico.

\section{Lógica bélica}

La verdadera valentía de un pueblo civilizado es estar dispuesto para el sacrificio al servicio del Estado, de tal modo que el individuo sólo constituye uno entre muchos. El coraje personal no es aquí lo importante, sino la subordinación a lo universal (Hegel, 2000: 379).

La lógica hegeliana ve en la guerra la posibilidad misma de realización de la moral. Mientras la moral es concebida como el abandono de las particularidades arbitrarias y caprichosas de los individuos en pos del acceso a la universalidad racional, la guerra es su realización efectiva al sacrificar el individuo en ella su querer subjetivo natural en interés de esa totalidad.

En el prefacio a su gran obra Totalidad e Infinito, Emmanuel Levinas señala los puntos de asiento de una lógica radicalmente diferente. ${ }^{1}$ El estado de guerra, desde su

1 Puede verse en la oposición de moral y política expuesta en estos parágrafos por Levinas, una referencia directa a lo dicho por Hegel en la obra citada: "Se ha discutido durante algún tiempo la oposición de moral y política y la exigencia de que la segunda sea conforme a la primera. Aquí sólo cabe observar 
perspectiva, suspende la moral, la vuelve irrisoria. La guerra -hija dilecta de la políticaparte del imperio de la totalidad, en cuyos dominios el encuentro intersubjetivo queda reducido a lucha entre egoísmos y a un conflicto permanente -desatado o latente- que somete a los individuos a un destino impersonal. En ella, los seres son avasallados en su identidad, "movilizados" por un orden objetivo del que no pueden sustraerse, obligados a renunciar a su propia sustancia y a desempeñar papeles que no desean, "en los que ya no se encuentran". Esta faz terrible del ser que se muestra en la guerra reposa, para Levinas, en la pretensión totalizante de la racionalidad occidental.

Esta pretensión, concomitante de la voluntad de universalidad que se expresa en la exigencia moral de acallamiento de las particularidades individuales, supone la reducción del yo y el otro a una neutralidad impersonal, la homogeneización de las diferencias en la univocidad del género "hombre" o de construcciones ideales equivalentes.

En su versión más acabada, el reduccionismo de la pretensión de totalidad determina a los individuos como "meros portadores de fuerzas que los dirigen a sus espaldas" (Levinas, 1977: 48); fuerzas y finalidades que les prestan un sentido y les prometen alcanzar su identidad al final del proceso, con el último acto de la historia. La totalidad les sustrae su singularidad irreductible, considerada desde su "objetividad" mera ilusión, y les promete una identidad más verdadera que les será conferida cuando la totalidad se haya desplegado plenamente. De este modo, la unicidad de cada presente se sacrifica en favor del porvenir, porque sólo éste puede darles su sentido objetivo.

La racionalidad a la que Levinas apuesta frente a esta lógica (que por lo demás, nos resulta muy familiar) opone al objetivismo de la guerra, la afirmación de la positividad de la subjetividad. Los individuos singulares son irreductibles al orden objetivo, poseen una identidad antes de la consumación de la historia, y en esto son sujetos interpelables en su plena responsabilidad.

¿En qué radica el polemos que la guerra escenifica entre objetividad y subjetividad? ¿Cuál es la violencia y cuál la positividad de la subjetividad avasallada en los conflictos bélicos? ¿Qué objetividad es la avasallante?

La violencia es la violencia del silencio a que la subjetividad es convocada. La violencia es, como toda violencia, la de la renuncia a la palabra. La guerra es el fracaso de la palabra, la de la diplomacia, en primer lugar, pero también la de las futuras víctimas no consultadas, la del mutismo horrorizado al que serán reducidas las poblaciones ante

sobre esto en general que el bienestar de un Estado tiene una justificación completamente distinta que el bienestar del individuo, y la sustancia ética, el Estado, tiene su existencia empírica, es decir, su derecho, inmediatamente, no en una existencia abstracta, sino en una existencia concreta, y que sólo esta existencia concreta, y no uno de los muchos pensamientos universales considerados como mandamientos morales, puede ser principio de su acción y comportamiento. La creencia de la presunta injusticia que la política debe tener siempre en esta presunta oposición, descansa antes bien en la superficialidad de la representación de moralidad, de la naturaleza del Estado y de sus relaciones con el punto de vista moral", (Hegel, 2000: 385). 
la patencia de la destrucción y de la muerte que se abatirá sobre ellas, la de las preguntas que no se podrá hacer, la de los testimonios que no se querrá escuchar. ${ }^{2}$

La ausencia de palabras ante el desgarro que el acontecimiento de la guerra efectúa en el tejido simbólico de una comunidad humana magnifica el impacto de su horror. ¿En qué consiste este horror y en qué medida su sujeto no son sólo los individuos aislados sino el tejido social común?

\section{Guerra, trauma y lazo social}

El padre del psicoanálisis concibió inicialmente al trauma como aquel acontecimiento cuya carga energética resultaba excesiva para los recursos del yo. ${ }^{3}$ Es decir, en términos económicos, un acontecimiento devenía traumático cuando excedía los recursos de que disponía el yo para recibirlo y tramitarlo. En la relectura hecha por Lacan, el trauma es aquello inasimilable, que no logró inscribirse en el lenguaje o en la cadena de representaciones que constituye la realidad psíquica inconsciente.

Mientras no acceda a la inscripción, eso que no ha podido representarse permanece en una eterna presencia, como fuera del tiempo, parece no poder pasar (por lo que estrictamente no pertenece al pasado). Tampoco puede ser tramitado subjetivamente, porque la falta de inscripción es concomitante con la falta de lugar en la estructura psíquica: sujeto, temporalidad e inscripción lingüística se originan en el mismo acto. Antes que posibilitar el advenimiento subjetivo, el trauma es justamente un golpe dislocante de la estructura. La vida del yo aparece como detenida en este punto y la repetición de lo traumático en síntomas, fenómenos psicosomáticos, sueños, etc., tiene la fuerza de la primera vez. En palabras de Freud: "Estos enfermos repiten regularmente en sus sueños la situación traumática; cuando se presentan ataques histeriformes...se averigua que el ataque responde a un traslado total [del paciente] a esa situación. Es como si estos enfermos no hubieran podido acabar con la situación traumática, como si ella se les enfrentara todavía a modo de una tarea actual insoslayable..." (Freud, 2009: 251).

Por cuanto no ha propiamente pasado, lo traumático no puede recordarse. Se trata de "pedazos de temporalidad congelados", que atestiguan el impacto de un desastre que "ha inmovilizado el tiempo" impidiendo el pasaje del pasado al presente (Davoine y Gaudillière, 2011: 41).

Lacan llama "real" a aquello que queda por fuera de la inscripción en el lenguaje: lo imposible de decir. Y lo describe, por definición, como aquello que "no cesa

\footnotetext{
2 “...la violencia no consiste tanto en herir y aniquilar como en interrumpir la continuidad de las personas, en hacerlas desempeñar papeles en los que ya no se encuentran, en hacerles traicionar, no sólo compromisos, sino su propia sustancia; en la obligación de llevar a cabo actos que destruirán toda posibilidad de acto" (Levinas, 1977: 47-48).

3 "Mas, la expresión 'traumática'...la aplicamos a una vivencia que en un breve lapso provoca en la vida anímica un exceso tal en la intensidad de estímulo que su tramitación o finiquitación (Aufarbeitung) por las vías habituales y normales fracasa, de donde por fuerza resultan trastornos duraderos para la economía energética" (Freud, 2009: 252).
} 
de no escribirse". Se trata de una ruptura en el discurso, como un agujero en la trama simbólica, en la cadena significante de la realidad psíquica.

La guerra es traumática en este sentido. No tanto por las balas materiales que hieren los cuerpos, cuanto por el hecho de que sus impactos dan de lleno en el corazón de los recursos simbólicos, única trama en la que un sujeto puede advenir. El núcleo de lo traumático reside en este quedarse desprovisto de los velos imaginario-simbólicos frente a lo real.

En la guerra, el recurso a la violencia es el signo del fracaso (o la desestimación) del universo simbólico de una comunidad humana. Debilitados los hilos de esa trama, los individuos -aislados y en su conjunto- quedan a merced de una voluntad de goce sin mediaciones, imposibilitados de desear. En este sentido, la guerra es perversa, porque su despliegue constituye un golpe a los cimientos de la estructura deseante de sus víctimas. Si esta estructura se cimienta en la alteridad, en el cuerpo y en el acceso al lenguaje, estos son los elementos desanudados en la disolución bélica.

En esta catástrofe de las garantías simbólicas e imaginarias, la alteridad está congelada en su posibilidad:

Toda catástrofe del orden social, doméstico u orgánico, corresponde a una pérdida de confianza, puntual o radical, en la seguridad de las leyes que rigen a los hombres, el universo o el cuerpo. Así, la alteridad cambia bruscamente de estatus. De garante de la buena fe, del que emanan la palabra y la permanencia de las leyes físicas, el otro se convierte en una superficie de signos y formas que hay que descifrar, sobre un fondo de palabras devaluadas (Davoine y Gaudllière, 2011: 127).

Si durante la guerra este fondo de palabras devaluadas provoca el derrumbe de los lazos sociales o los limita a espacios insulares, después de la guerra el daño persiste a distintos niveles en el silencio de las víctimas respecto de lo padecido y en la dificultad para encontrar interlocutores capaces de prestar oído a lo terrible. ${ }^{4}$ Lo traumático persistirá hasta hallar un otro a quien hablar. Entre los protagonistas de la guerra, "todo sucede como si cada víctima psíquica encarnara la dehiscencia del tejido social. A falta de otro a quien hablar, el trauma reduce al individuo a una interioridad invadida por la angustia de aniquilación, al espanto...". 5

El espanto de la exposición a lo real sin trámite sólo puede ser conjurado con el re-entramado del tejido simbólico. Esto supone que vuelva a ser posible establecer un

\footnotetext{
4 "Devant l'horreur qui dépasse une certaine intensité, la plupart d'entre nous cessons d'être réceptifs" (Eva Bravant, 2008: 44).

5 "Tout se passe comme si chaque victime psychique incarnait la déhiscence du tissu social. Le trauma réduit l'individu (faute d'autre à qui parler) à une intériorité envahie par l'angoisse de néantisation, à l'épouvante..." (Claude Barrois citado en Briole y col., 1994: 74-75).
} 
lazo social. Su establecimiento no podrá consistir en aliarse especularmente a otros en una causa común, adormeciendo la propia singularidad en la identificación a un colectivo ilusorio que se compacta negando toda fisura y proyectando toda falla hacia el afuera, en la construcción imaginaria de un enemigo. Esta figura deficitaria de la alteridad suele ser un recurso a mano ante el golpe asestado por la guerra a las posibilidades del lazo social, pero no es capaz de restablecerlo en la medida en que supone un acallamiento ilusorio de la propia singularidad -concomitante con la denegación de la barra que recae sobre todo sujeto en tanto hablante y que lo separa para siempre de la completud. Hablar a otro sólo es posible desde este vacío constitutivo de la subjetividad. Y establecer un lazo social implica encontrar un otro a quien hablar. Levinas definirá la paz en asociación con esa aptitud para la palabra y la interlocución, en la que los individuos llegan a ser “...entes que pueden hablar, en lugar de prestar sus labios a una palabra anónima de la historia" (Levinas, 1977: 49).

Se tratará después de la guerra, y ante su acto perverso de sustitución de la palabra por el acto y de su explosión de los cimientos de la estructura deseante, de abrir nuevamente las vías a la palabra, para que algo pueda ser dicho a alguien que pueda escuchar ${ }^{6}$, de modo que, alrededor de eso irrepresentable, puedan irse inscribiendo letras de borde que permitan su ingreso -extraño- a la circulación discursiva.

Si hemos podido correr el eje de nuestra comprensión de la fuerza destructiva de la guerra desde la destrucción patrimonial y física a la catástrofe simbólica, y si esta operación nos permite medir mejor su impacto en el tejido social, podemos ahora avanzar sobre una consideración de nuevo cuño del estatuto asignable al gesto historiográfico en este contexto.

\section{La significación del gesto historiográfico. La pregunta por su inteligibilidad}

Ante el panorama descripto, el debate acerca del carácter del gesto de la escritura de la historia requiere ser conducido a un nivel diferente. En este marco, lo que ocupa el primer plano no es tanto la aspiración a la objetividad del relato histórico ni la discusión en torno a la posibilidad de recuperar los hechos en su verdad. El acento ya no recae sobre la operación de la representación historiográfica y su pretensión veritativa, sino sobre la posición del historiador frente a lo traumático y sus posibilidades para ofrecer en el relato una superficie de escritura. El acento recae sobre la ética del gesto, en el sentido que esta palabra tiene en el psicoanálisis, y también en el seno de la filosofía levinasiana. Se trata de otra inteligibilidad, cuya diferencia testimonia, en todo caso, que la significación no se reduce al concepto y a la representación.

Se trata de aquella posición ética del historiador capaz de conducir lo traumático a la escritura, que no será atribuible sin más a toda modalidad historiográfica. La trascendencia de esta inscripción para la reconstrucción de las condiciones de posibilidad

\footnotetext{
${ }_{6}$ En psicoanálisis, esto puede darse en el seno de una "transferencia": "Una transferencia que apunte a la génesis de un nuevo lazo social sobre las ruinas de la lealtad y, por lo tanto, de la palabra", (Davoine y Gaudillière, 2011: 203).
} 
del lazo social no deja lugar a dudas sobre el derecho de esta otra significación a un lugar en la escena académica.

"Historizar" es, precisamente, contribuir a esa inscripción: que alrededor de lo irrepresentable algo pueda ser escrito y de este modo se articule un discurso que lo bordee aún sin poder tocarlo plenamente. Historizar es volver a traer al flujo del tiempo algo que había permanecido extraño a él, permitir su encabalgamiento en el discurso $\mathrm{y}$, de este modo, su pasar, su incorporación al discurrir temporal como huella y su apertura a un horizonte de futuro. ${ }^{7}$

Lo que importa aquí es que el gesto historiográfico pueda aportar a ese bordeamiento de lo real con su escritura, abriendo vías a la circulación de la palabra. Algo de la verdad se dirá en los intersticios de esta circulación, en un diálogo infinito de las distintas versiones singulares de los hechos.

El problema historiográfico no residirá entonces en alcanzar el acuerdo último de las distintas versiones o en reducir su número, sino en habilitar la posibilidad de su coexistencia, mientras éstas sean genuinas y suficientemente permeables para dejar existir cabe sí las diferentes. Lo contrario a la verdad no será la parcialidad ni el error sino la totalización esférica de la pretensión de certeza y representación absolutas. En la posición de la certeza y de la posesión de la verdad, otra vez el tiempo se detiene porque se sustancia y paraliza en lo ya poseído. ¿Para qué el tiempo y para qué los otros cuando ya está todo dicho? La condición de la circulación de lo verdadero es la renuncia al cierre totalizante, dador de sentido, que sólo permite taponar ilusoriamente lo irrepresentable, perpetuando sus efectos destructivos e impidiendo tramitarlo e inscribirlo.

Una escritura que pueda restablecer las garantías de la palabra será aquella que no caiga en la misma perversión del lazo social operada por la guerra: la de la mentira, la de las parcialidades interesadas, la del cierre de sentido que impide la circulación significante. La perversión de la "última palabra". La perversión de una palabra sin otro. Una palabra con los caracteres de la imagen, clausurante, debe ceder espacio a una palabra que asegure la posibilidad de hablar y la articulación de un interlocutor a quien dirigir la palabra. Una historia con más de un logos es la única capaz de asegurar las garantías de la palabra y favorecer el discurrir restituyente del lazo social. La cualidad historiográfica del gesto del historiador deberá medirse entonces, no tanto (o no sólo) por su virtud de representación sino por su posibilidad de re-entramar en su escritura esa aptitud, ofreciendo un discurrir que no clausure esa posibilidad en un relato anónimo y total.

Cuando se trate de escribir para construir la ilusión de plenitud de la propia interpretación, desestimando absolutamente otras versiones, cercenando en su inicio toda posibilidad de diálogo y permaneciendo en la alternativa especular de "o nosotros o ustedes", el relato histórico podrá ser intachable en sus opciones epistemológicas y en su proceder metodológico y podrá aprovechar todos los resguardos críticos para

\footnotetext{
7 "En esas áreas donde el proceso de simbolización se revela imposible no tiene ningún sentido evocar el pasado, ni siquiera como una 'repetición' que haría huella. El futuro, tiempo gramatical del deseo, es igualmente imposible de encarar", Ibid 77.
} 
asegurarse en su verdad, pero no será racional. Lo sensato, lo racional no puede continuar midiéndose según la antigua inteligibilidad de la certeza, que acoge la guerra como uno de sus destinos posibles. Una nueva significación de lo racional hace residir lo sensato en aquellas condiciones discursivas que posibilitan el anudamiento de una trama capaz de garantizar a todos el acceso a la palabra. Reconociendo la imposibilidad de tener toda la verdad, aceptando la porosidad de los propios presupuestos a la parcialidad y al error, y pudiendo de este modo ser permeables a entrar en relación con la visión extraña, lo verdadero podrá acontecer. Porque lo verdadero está justamente en ese no-todo, en las posibilidades que ese quiebre de la pretensión totalitaria abre a la circulación significante, para que allí entre sus pliegues algo pueda ser dicho.

\section{Referencias bibliográficas}

Bravant, E. 2008. "Penser le traume, panser la victime”. En: Le Coq-heron, 4, n 195 , pp. 43-50.

Brezzo, L. 2014. "La guerra del Paraguay a través de la memoria de sus actores: el proyecto historiográfico de Estanislao Zeballos", en: Nuevo Mundo Mundos Nuevos [En línea], Colloques, puesto en línea el 1 de febrero de 2006, consultado el 10 de septiembre de 2014, URL: http://nuevomundo.revues.org/1677; DOI : 10.4000/nuevomundo. 1677

Brezzo, L. 2009-2010. "La guerra de la Triple Alianza en la primera persona de los vencidos: El hallazgo y la incorporación de la sección Estanislao S. Zeballos del Ministerio de Defensa de Paraguay". En: Anuario n ${ }^{\circ} 22$, Escuela de Historia, Revista Digital $\mathrm{n}^{\circ}$ 1, Facultad de Humanidades y Artes, UNR, pp.217-235. URL: $\quad$ http://rephip.unr.edu.ar/bitstream/handle/2133/3684/57-278-1-PB. pdf? sequence $=1$

Brezzo, L. 2004. "La guerra de la Triple Alianza en los límites de la ortodoxia: mitos y tabúes". En: Revista Universum, n 19, vol 1, pp. 10-27.

Briole, G. y col. 1994. Le traumatisme psychique: rencontre et devenir, Paris, Masson.

Davoine, F. y Gaudillière, J. M. 2011. Historia y trauma, La locura de las guerras, Buenos Aires, Fondo de Cultura Económica.

Freud, S. 2010. “Recordar, repetir, reelaborar”. En: Obras completas, tomo XII, Buenos Aires, Amorrortu, pp.145-157.

Freud, S. 2009. “ $18^{\circ}$ Conferencia: La fijación al trauma, lo inconsciente”. En: Obras completas, tomo XVI: Conferencias de introducción al psicoanálisis (parte III), Buenos Aires, Amorrortu, pp. 250-261.

Freud, S. 2010. "Más allá del principio del placer”. En: Obras completas, tomo XVIII, Buenos Aires, Amorrortu, pp.1-136.

Jelin, E. 2001. "Historia, memoria social y testimonio, o la legitimidad de la palabra". En: Iberoamericana, 1, 1, pp. 87-97.

Hegel, G. F. W. 2000. Rasgos fundamentales de la filosofía del Derecho, Madrid, Biblioteca Nueva. 
Lacan, J. 2011. Seminario X: "La angustia”, Buenos Aires, Paidós.

Lacan, J. 1985. Seminario XX: “Aún”, Barcelona, Paidós.

Laurent, E. 2002. "El revés del trauma”. En: Virtualia, Revista digital de la EOL, n6, junio-julio, pp. 2-7.

Levinas, E. 1977. Totalidad e Infinito, Ensayo sobre la Exterioridad, tr. Daniel Guillot, Salamanca, Sígueme.

Yospe, J. 2007. Genocidio, monoteísmo y escritura, Ensayos psicoanalíticos, Buenos Aires, Centro Psicoanalítico Norte. 
